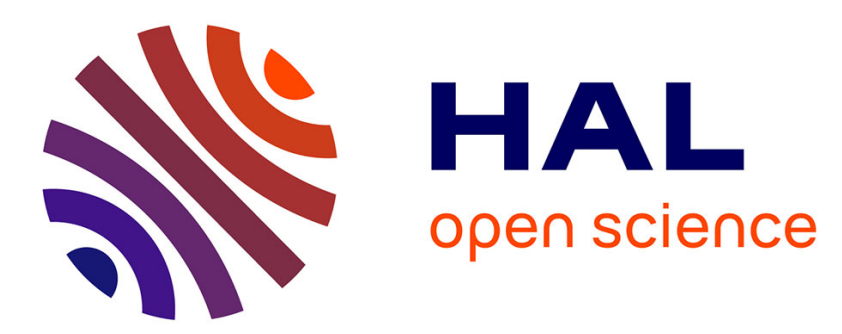

\title{
A new ternary nitride La2GaN3: Synthesis and crystal structure
}

François Cheviré, Francis J. Disalvo

\section{To cite this version:}

François Cheviré, Francis J. Disalvo. A new ternary nitride La2GaN3: Synthesis and crystal structure. Journal of Alloys and Compounds, 2008, 457 (1-2), pp.372-375. 10.1016/j.jallcom.2007.02.110 . hal00864760

\section{HAL Id: hal-00864760 \\ https://hal.science/hal-00864760}

Submitted on 18 Sep 2015

HAL is a multi-disciplinary open access archive for the deposit and dissemination of scientific research documents, whether they are published or not. The documents may come from teaching and research institutions in France or abroad, or from public or private research centers.
L'archive ouverte pluridisciplinaire HAL, est destinée au dépôt et à la diffusion de documents scientifiques de niveau recherche, publiés ou non, émanant des établissements d'enseignement et de recherche français ou étrangers, des laboratoires publics ou privés. 


\title{
A new ternary nitride $\mathrm{La}_{2} \mathrm{GaN}_{3}$ : synthesis and crystal
}

\section{structure.}

François Cheviré, Francis J. DiSalvo*.

Department of Chemistry and Chemical Biology, Cornell University, Ithaca, NY 14853, USA

Phone: +1 607-255-7238

Fax: +1 607-255-4137

*fjd3@cornell.edu

\section{Keywords}

Nitride materials; Crystal growth; X-ray diffraction; Crystal and structure symmetry

\begin{abstract}
The ternary nitride $\mathrm{La}_{2} \mathrm{GaN}_{3}$ was synthesized from the elements and an excess of sodium and gallium at $900^{\circ} \mathrm{C}$ in a sealed niobium tube. $\mathrm{La}_{2} \mathrm{GaN}_{3}$ is yellow colored and crystallizes with the $\mathrm{Ba}_{2} \mathrm{ZnO}_{3}$ structure [monoclinic space group C2/c (No.15), $a=$ 5.6709(5) $\mathrm{A}, b=10.945(1) \AA, c=11.986(1) \AA, \beta=93.591(5)^{\circ}, V=742.54(12) \AA^{3}, Z=$ 8] and is isostructural with the $\mathrm{A}_{2}{ }^{\mathrm{II}} \mathrm{M}^{\mathrm{V}} \mathrm{N}_{3}$ nitrides, $\operatorname{Sr}(\mathrm{Ba})_{2} \mathrm{TaN}_{3}, \operatorname{Sr}(\mathrm{Ba})_{2} \mathrm{NbN}_{3}$, $\mathrm{Ca}(\mathrm{Sr})_{2} \mathrm{VN}_{3}$. The structure contains infinite chains of $\mathrm{GaN}_{4}$ tetrahedral anions, ${ }_{\infty}^{1}\left[\mathrm{GaN}_{2} \mathrm{~N}_{2 / 2}\right]^{6-}$.
\end{abstract}




\section{Introduction}

Binary nitrides of the main group elements, such as $\mathrm{GaN}, \mathrm{Si}_{3} \mathrm{~N}_{4}$, and $\mathrm{AlN}$, are technologically of interest. Especially gallium nitride is a key material for blue/ultraviolet light emitting diodes (LEDs) and lasers as well as for sensors for UVlight. The synthesis of new nitrides is thus a field of growing interest in solid-state chemistry in the search for new materials with promising properties and applications. However, very little is presently known about multinary gallium nitrides. DiSalvo et al. have reported several compounds with nitridogallate anions in the past ten years which often show novel structures. For example, $\mathrm{Sr}_{3} \mathrm{GaN}_{3}$ and $\mathrm{Sr}_{6} \mathrm{GaN}_{5}$ contain isolated planar $\left[\mathrm{GaN}_{3}\right]^{6-}$ anions [1], $\mathrm{Sr}_{3} \mathrm{Ga}_{2} \mathrm{~N}_{4}$ [2] and $\mathrm{Ba}_{3} \mathrm{Ga}_{2} \mathrm{~N}_{4}$ [3] contain edge-shared $\left[\mathrm{GaN}_{4 / 2}\right]^{3-}$ tetrahedra, while $\alpha-\mathrm{Ca}_{3} \mathrm{Ga}_{2} \mathrm{~N}_{4}$ and $\mathrm{Sr}_{3} \mathrm{Ga}_{3} \mathrm{~N}_{5}$ [2] and the recently reported quaternary nitride $\mathrm{LiCaGaN}_{2}$ [4] exhibit structures based on corner-shared $\left[\mathrm{Ga}_{2} \mathrm{~N}_{6}\right]$ dimers which are formed by two edge-sharing tetrahedra. Let us finally note the two compounds $\beta-\mathrm{Ca}_{3} \mathrm{Ga}_{2} \mathrm{~N}_{4}[5]$ and $\mathrm{LiSrGaN}_{2}[6]$ have structures that are based on interpenetrating networks. The anti-perovskite compound $\mathrm{Nd}_{3} \mathrm{GaN}$ has been mentioned in the literature and is the only reported compound in a rare-earth/gallium/nitrogen system but it cannot be described in terms of anionic nitridometalate species and fully oxidized cations as the nitrogen atoms are not bonded to gallium atoms in the structure [7].

Here we report the synthesis and the crystal structure of the first reported rareearth nitridogallate compound, $\mathrm{La}_{2} \mathrm{GaN}_{3}$ that contains infinite chains of corner-sharing $\left[\mathrm{GaN}_{2} \mathrm{~N}_{2 / 2}\right]^{6-}$ tetrahedra. 


\section{Experimental}

Clear yellow and air stable crystals of $\mathrm{La}_{2} \mathrm{GaN}_{3}$ were first observed as a byproduct while investigating the ternary lanthanum-tungsten-nitrogen system using an excess of sodium and gallium as a flux. The compound was further successfully synthesized from a tungsten-free reaction as described in the following procedure. Due to the air sensitivity of the reagents, all manipulations were carried out in an argonfilled glove box. $\mathrm{Na}, \mathrm{Ga}, \mathrm{La}$ and $\mathrm{NaN}_{3}$ were placed into a niobium tube $(\mathrm{OD} \approx 1 \mathrm{~cm}$, length $\approx 12 \mathrm{~cm}$ ) in the atomic ratios of $\mathrm{Na}: \mathrm{Ga}: \mathrm{La}: \mathrm{N}_{2}$ were $6: 4: 1: 3$. The corresponding masses are $\mathrm{Na}$ (Aldrich, A.C.S reagent grade) $83 \mathrm{mg}, \mathrm{Ga}(99.99 \%) 200 \mathrm{mg}$, La (filled from rod, Jonhson Matthey Company) $100 \mathrm{mg}$ and NaN3 (99.9\%) $47 \mathrm{mg}$. The niobium container was sealed under argon in a Centorr Associates arc furnace and then itself sealed under vacuum in a fused silica tube in order to protect it from subsequent oxidation during heating. The silica tube was then placed into a muffle furnace, heated up to $900^{\circ} \mathrm{C}$ in $15 \mathrm{~h}$, held at temperature for $36 \mathrm{~h}$. Then the furnace was allowed to cool to RT over $100 \mathrm{~h}$. Following this heating sequence, the niobium tube was opened and unreacted sodium was removed by evaporation from the products by heating the niobium tube to $350^{\circ} \mathrm{C}$ under a pressure of $\sim 10^{-6}$ bar for $8 \mathrm{~h}$.

The products of the reaction were analyzed with powder X-ray diffraction using a Scintag $2000 \theta-\theta$ diffractometer with $\mathrm{Cu} K \alpha$ radiation. The sample was prepared in an argon-filled glove box and covered with Mylar film to prevent reaction with air and moisture. Single crystal X-ray diffraction data were obtained using a Brucker X8 Apex II diffractometer equipped with 4K CCD detector and graphite monochromatized MoK $\alpha$ radiation $(\lambda=0.07107 \AA)$. The Brucker software package SAINT [8] was used 
to integrate the data, an empirical absorption correction was applied using SADABS [9] and the initial input files for solving the structure prepared by XPREP [10]. The integrated data were analyzed with the SHELX97 [11] suite of programs within WinGX [12]. The La:Ga ratio of $\mathrm{La}_{2} \mathrm{GaN}_{3}$ was determined by standardless electron microprobe analysis performed with a JEOL 8900 electron microprobe.

\section{Results and Discussion}

After the sodium was removed from the sample, the tube was moved back into the argon-filled glove box. The remaining product appeared as a dark gray, silvery mass in which no crystals were clearly visible by eye. A fraction of the product was ground in an agate mortar for powder X-ray diffraction analysis but only $\mathrm{LaN}, \mathrm{Na}_{\mathrm{x}} \mathrm{Ga}_{\mathrm{y}}$ and $\mathrm{La}_{\mathrm{x}} \mathrm{Ga}_{\mathrm{y}}$ phases could be identified. Another portion of the reaction product was placed into polybutene oil for inspection under an optical microscope. Small sized clear yellow and air stable crystals were apparent with two distinct shapes: block crystals and thin long plates. Several of them were analyzed and all were consistent with a monoclinic symmetry independent of the shape of the selected crystal. A suitable crystal with approximate $80 * 60 * 60 \mu \mathrm{m}^{3}$ dimensions was chosen for data collection. Its structure was solved in $C 2 / \mathrm{c}$ (No. 15). Details of the refinement are shown in Table 1. No extra symmetry was found by ADDSYM [12]. The atomic coordinates were standardized with STRUCTURE TIDY [13] and are shown in Table 2. The anisotropic displacement factors are detailed in Table 3. In order to verify the elemental composition found by the single crystal XRD solution, semi-quantitative electron microprobe spectroscopy measurement were carried out. Results were similar for the 
two different shapes of crystal and revealed a La:Ga ratio of 1.9:1. These data are within the expected errors for a standardless measurement. No signal corresponding to sodium, gallium or niobium were observed. The presence of nitrogen was confirmed by wavelength dispersive spectroscopy.

$\mathrm{La}_{2} \mathrm{GaN}_{3}$ crystallizes with the $\mathrm{Ba}_{2} \mathrm{ZnO}_{3}$ structure (Fig. 1) [14] and is isostructural to the $\mathrm{A}_{2}{ }^{\mathrm{II}} \mathrm{M}^{\mathrm{V}} \mathrm{N}_{3}$ nitrides: $\mathrm{Ca}(\mathrm{Sr})_{2} \mathrm{VN}_{3}[15,16], \mathrm{Sr}(\mathrm{Ba})_{2} \mathrm{NbN}_{3}[17,18]$ and $\operatorname{Sr}(\mathrm{Ba})_{2} \mathrm{TaN}_{3}[19,20]$. The structure is built up by $\mathrm{La}^{3+}$ cations and nitridogallate anions which form parallel infinite chains of vertex-linked $\left[\mathrm{GaN}_{3}\right]^{4-}$ group along [100] with a pattern that repeats after two tetrahedra (Fig. 2). One characteristic of those chains is the difference between $\mathrm{Ga}-\mathrm{N} 4-\mathrm{Ga}$ and $\mathrm{Ga}-\mathrm{N} 1-\mathrm{Ga}$ angle values, i.e. $176.6^{\circ}$ and $111.1^{\circ}$, where N4 and N1 are the bridging nitrogen. Such chains can be described after Liebau [21] as "zweier single chains" and the chain torsion angle can be defined by N1-N4$\mathrm{N} 1$ in $\mathrm{La}_{2} \mathrm{GaN}_{3}$ with a value of $135.2^{\circ}$. By comparison, the chain angle in isostructural $\mathrm{Ba}_{2} \mathrm{ZnO}_{3}$ is $139.9^{\circ}$, and the $\mathrm{Zn}-\mathrm{O}_{\text {bridging }}-\mathrm{Zn}$ angles are $178.3^{\circ}$ and $115.3^{\circ}$. The monoclinic distortion in $\mathrm{La}_{2} \mathrm{GaN}_{3}\left(\beta=93.59^{\circ}\right)$ is similar to that of $\mathrm{Ba}_{2} \mathrm{ZnO}_{3}(\beta=$ $93.63^{\circ}$ ) but larger than the ones observed in the $\mathrm{A}^{\mathrm{II}}{ }_{2} \mathrm{M}^{\mathrm{V}} \mathrm{N}_{3}$ series where $90.99^{\circ}<\beta<$ $92.34^{\circ}$. The average distances of gallium to bridging nitrogen and terminal nitrogen are $1.936 \AA$ and $1.983 \AA$ A respectively. Those distances are slightly shorter than the ones observed in the ternary nitrides $\mathrm{A}_{3} \mathrm{Ga}_{2} \mathrm{~N}_{4}(\mathrm{~A}=\mathrm{Sr}, \mathrm{Ba})$ that contain infinite edge sharing chains ${ }_{\infty}^{1}\left[\mathrm{GaN}_{4 / 2}\right]^{3-}$, i.e. $2.005 \AA$ and $2.017 \AA$ respectively for $\mathrm{Sr}$ and $\mathrm{Ba}[2,3]$. The $\mathrm{La}^{3+}$ are coordinated to seven nitrogen atoms with distances ranging from $2.45 \AA$ to $3.22 \AA$ (Table 4). $\mathrm{La}(1)$ is coordinated to nitrogen in a monocapped trigonal prismatic geometry while for $\mathrm{La}(2)$ a distorted pentagonal bipyramid is observed (Fig. 2). The average La-N bond length is $\sim 2.70 \AA$, comparable to that reported in the binary nitride 
LaN ( $2.65 \AA$ ) or in the lanthanum-containing ternary nitrides of the $\mathrm{RE}_{3} \mathrm{M}_{2} \mathrm{~N}_{6}$ family where $\mathrm{RE}=$ rare earth element and $\mathrm{M}=\mathrm{V}(\sim 2.68 \AA)[22], \mathrm{Nb}(\sim 2.73 \AA), \mathrm{Ta}(\sim 2.63$ A) [23] or $\mathrm{Cr}(\sim 2.63 \AA)[24]$.

\section{Conclusion}

The new nitride $\mathrm{La}_{2} \mathrm{GaN}_{3}$ has been synthesized and is the first reported ternary compound in a rare-earth/gallium/nitrogen system which can be described in terms of anionic nitridometalate species and fully oxidized cations. It crystallizes in the $\mathrm{Ba}_{2} \mathrm{ZnO}_{3}$ structure-type.

\section{Acknowledgment}

This work was supported by NSF grant number DMR-0602526. We thank Dr. Emil Lobkovsky for help with the single crystal data collection and structure solution, and John hunt for help with the SEM Microprobe. The Microprobe is supported by the Cornell Center for Materials Research Shared Experimental Facilities, funded through the National Science foundation Materials Research Science and Engineering program DMR-0520404. 


\section{References}

[1] D. G. Park, Z. A. Gál, F. J. DiSalvo, Inorg. Chem. 42 (2003) 1779-1785.

[2] S. J. Clarke, F. J. DiSalvo, Inorg. Chem. 36 (1997) 1143-1148.

[3] H. Hisanori, F. J. DiSalvo, Acta Cryst. C52 (1996) 760-761.

[4] M. S. Bailey, F. J. DiSalvo, J. Alloys Comp. 417 (2006) 50-54.

[5] S. J. Clarke, F. J. DiSalvo, J. Alloys Comp. 274 (1998) 118-121.

[6] D. G. Park, Z. A. Gál, F. J. DiSalvo, J. Alloys Comp. 353 (2003) 107-113.

[7] H. Haschke, H. Nowotny, F. Benesovsky, Monatsch. Chem. 98 (1967) 21572163.

[8] Brucker, SAINT Plus: Software for the CCD system, Brucker Analytical X-ray system, Madison, WI, 2003.

[9] G. M. Sheldrick, SADABS, Institute für Anorganische Chemie der Universität Göttingen, Göttingen, Germany, 2003.

[10] Brucker, XPREP (Version 6.14), Brucker Analytical X-ray system, Madison, WI, 2003.

[11] G. M. Sheldrick, SHELXS97 and SHELXL97, University of Göttingen, Germany, 1997.

[12] L. J. Farrugia, J. Appl. Crystallogr. 32 (1999) 837-838.

[13] L. M. Gelato, E. Parthé, J. Appl. Crystallogr. 20 (1987) 139. 
[14] M. Scheikowski, H. Müller-Buschbaum, Z. Anorg. Allg. Chem. 612 (1992) 1720.

[15] D. A. Zherebstov, L. G. Akselrud, R. Niewa, Z. Kristallogr. NCS 217 (2002) 469.

[16] D. H. Gregory, M. G. Barker, P. P. Edwards, D. J. Siddons, Inorg. Chem. (1995) 3912-3916.

[17] X. Z. Chen, H. A. Eick, W. Lasocha, J. Solid State Chem. 138 (1998) 297-301.

[18] O. Seeger, M. Hofmann, J. Strähle, J. P. Laval, B. Frit, Z. Anorg. Allg. Chem. 620 (1994) 2008-2013.

[19] F. K.-J. Helmlinger, P. Höhn, R. Kniep, Z. Naturforsch. 48b (1993) 1015-1018.

[20] A. Bowman, D. H. Gregory, J. Alloys Comp. 348 (2003) 80-87.

[21] F. Liebau, Structural Chemistry of silicates, Springer-Verlag, Heidelberg, 1985.

[22] Z. A. Gál, L. Cario, F. J. DiSalvo, Solid State Sci. 5 (2003) 1033-1036.

[23] L. Cario, Z. A. Gál, T. P. Braun, F. J. DiSalvo, B. Blaschkowski, H.-J. Meyer, J. Solid State Chem. 162 (2001) 90-95.

[24] F. Cheviré, C. Ranjan, F. J. DiSalvo, to be published. 


\section{Figures and tables captions}

Figure 1: Structure of $\mathrm{La}_{2} \mathrm{GaN}_{3}$ showing the arrangement of the corner sharing tetrahedral ${ }_{\infty}^{1}\left[\mathrm{GaN}_{2} \mathrm{~N}_{2 / 2}\right]^{4-}$ chains.

Figure 2: Depiction of the ${ }_{\infty}^{1}\left[\mathrm{GaN}_{2} \mathrm{~N}_{2 / 2}\right]^{4-}$ chains and coordination polyhedrons of La in $\mathrm{La}_{2} \mathrm{GaN}_{3}$.

Table 1: Crystal data and structure refinement for $\mathrm{La}_{2} \mathrm{GaN}_{3}$.

Table 2: Atomic coordinates and values of $U_{\text {eq }}$, the equivalent isotropic displacement parameter $\left(\AA^{2} \times 10^{3}\right)$, for $\mathrm{La}_{2} \mathrm{GaN}_{3}$.

Table 3:Anisotripic displacement parameters $\left(\AA^{2} \times 10^{3}\right)$ for $\mathrm{La}_{2} \mathrm{GaN}_{3}$.

Table 4: Selected bond lengths for $\mathrm{La}_{2} \mathrm{GaN}_{3}(\AA)$. 
Figure 1

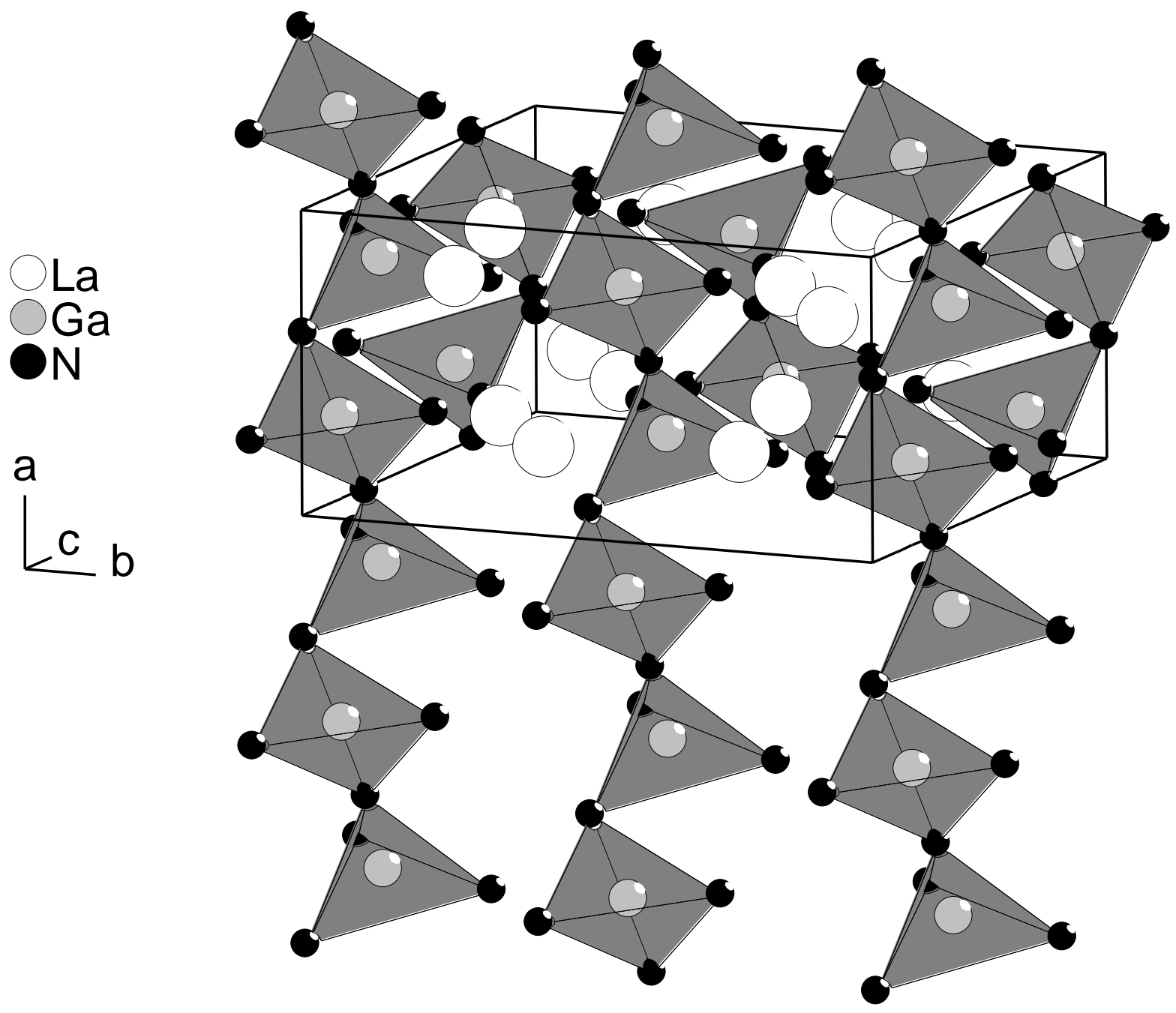


Figure 2
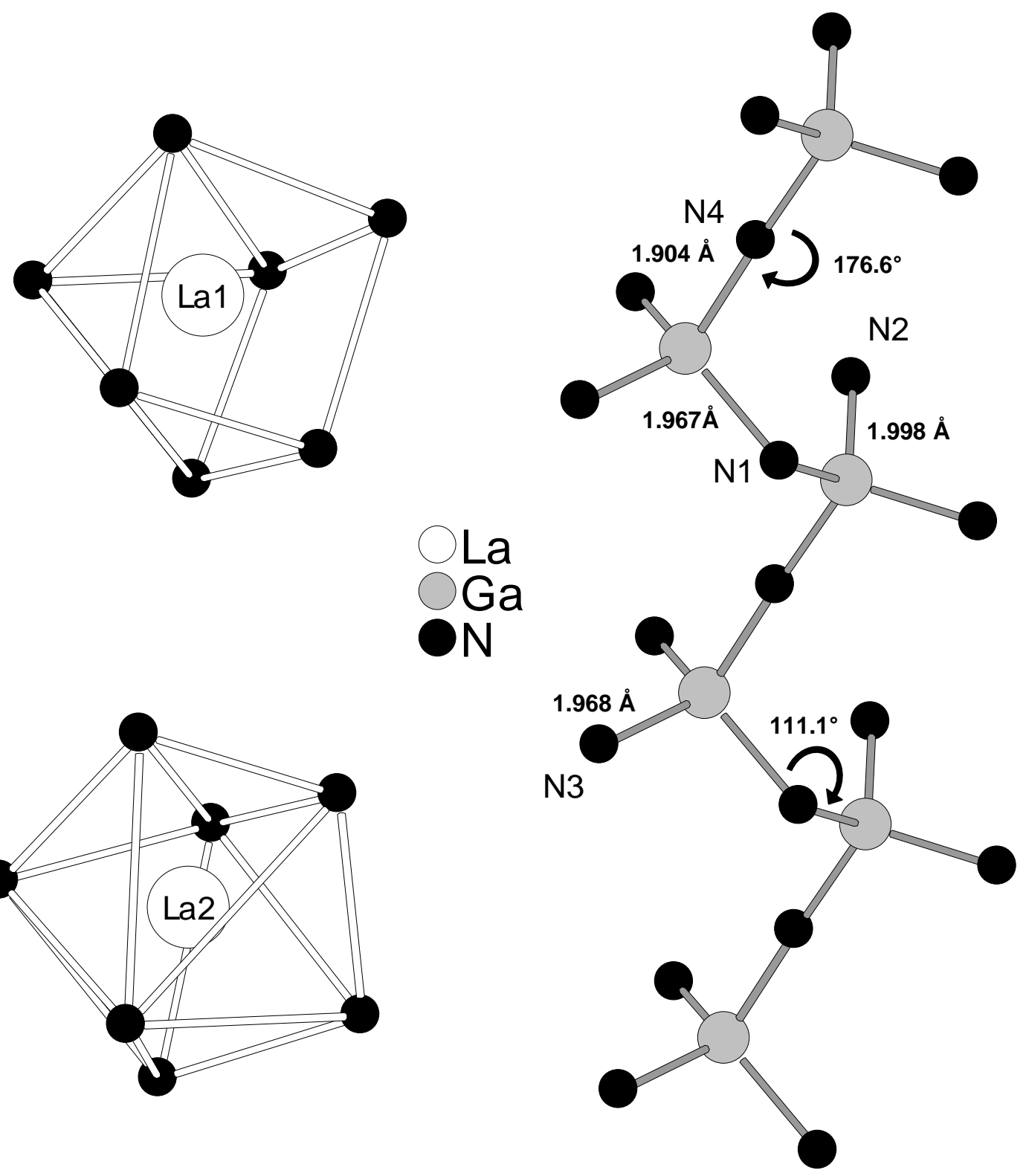
Table 1

\begin{tabular}{ll}
\hline Empirical formula & $\mathrm{La}_{2} \mathrm{GaN}_{3}$ \\
Formula weight $(M)$ & 389.57 \\
Temperature $(\mathrm{K})$ & $167(2)$ \\
Crystal system & Monoclinic \\
Space group & $C 2 / \mathrm{c}$ \\
$a(\AA)$ & $5.6709(5)$ \\
$b(\AA)$ & $10.945(1)$ \\
$c(\AA)$ & $11.986(1)$ \\
$\beta\left(^{\circ}\right)$ & $93.591(5)$ \\
Volume $\left(\AA^{3}\right)$ & $742.54(12)$ \\
$Z$ & 8 \\
Density (calculated) $\left(\mathrm{Mg} \mathrm{m}{ }^{-3}\right)$ & 6.970 \\
Absorption coefficient $(\mu)\left(\mathrm{mm}^{-1}\right)$ & 29.584 \\
Reflections collected & 6330 \\
Independent reflections & $1843\left[R_{\text {int }}=0.0251\right]$ \\
Goodness-of-fir on $F^{2}$ & 1.014 \\
Final $R$ indices $[I>2 \sigma(\mathrm{I})]$ & $R 1=0.029$ \\
$\mathrm{R}$ indices (all data) & $\mathrm{w} R 2=0.0401$ \\
\hline
\end{tabular}


Table 2

\begin{tabular}{llllll}
\hline Atom & $\begin{array}{l}\text { Wyckoff } \\
\text { position }\end{array}$ & $x$ & $y$ & $z$ & $U_{\text {eq }}$ \\
\hline La1 & $8 f$ & $0.2385(1)$ & $0.2074(1)$ & $0.3488(1)$ & $4(1)$ \\
La2 & $8 f$ & $0.2585(1)$ & $0.3945(1)$ & $0.0744(1)$ & $4(1)$ \\
$\mathrm{Ga}$ & $8 f$ & $0.2993(1)$ & $0.0016(1)$ & $0.1629(1)$ & $3(1)$ \\
$\mathrm{N} 1$ & $4 e$ & 0 & $0.4000(3)$ & 0.25 & $5(1)$ \\
$\mathrm{N} 2$ & $8 f$ & $0.3220(5)$ & $0.1783(3)$ & $0.1305(2)$ & $6(1)$ \\
$\mathrm{N} 3$ & $8 f$ & $0.2222(5)$ & $0.1002(2)$ & $0.5280(2)$ & $7(1)$ \\
$\mathrm{N} 4$ & $4 e$ & 0 & $0.0068(4)$ & 0.25 & $8(1)$ \\
\hline
\end{tabular}

$U_{\text {eq }}$ is defined as one third of the trace of the orthogonalized $U^{i j}$ tensor. 
Table 3

\begin{tabular}{lllllll}
\hline Atom & $U^{11}$ & $U^{22}$ & $U^{33}$ & $U^{23}$ & $U^{13}$ & $U^{12}$ \\
\hline La1 & $4(1)$ & $3(1)$ & $4(1)$ & $0(1)$ & $0(1)$ & $0(1)$ \\
La2 & $4(1)$ & $3(1)$ & $3(1)$ & $0(1)$ & $0(1)$ & $0(1)$ \\
Ga & $3(1)$ & $3(1)$ & $3(1)$ & $0(1)$ & $0(1)$ & $0(1)$ \\
N1 & $6(2)$ & $4(2)$ & $5(2)$ & 0 & $-2(1)$ & 0 \\
N2 & $6(1)$ & $4(1)$ & $7(1)$ & $1(1)$ & $1(1)$ & $-2(1)$ \\
N3 & $8(1)$ & $5(1)$ & $7(1)$ & $0(1)$ & $0(1)$ & $0(1)$ \\
N4 & $7(2)$ & $11(2)$ & $6(2)$ & 0 & $0(1)$ & 0 \\
\hline \multicolumn{7}{l}{ The anisotropic displacement factor takes the form $-2 \pi^{2}\left[h^{2} a^{* 2} U^{11}+\cdots+2 h k a^{*} b^{*} U^{12}\right]$}
\end{tabular}


Table 4

\begin{tabular}{ll}
\hline $\mathrm{La} 1-\mathrm{N} 1$ & $2.734(3)$ \\
$\mathrm{La} 1-\mathrm{N} 2$ & $2.509(3), 2.707(3), 3.220(3)$ \\
$\mathrm{La} 1-\mathrm{N} 3$ & $2.454(3), 2.574(3)$ \\
$\mathrm{La} 1-\mathrm{N} 4$ & $2.802(3)$ \\
\hline $\mathrm{La} 2-\mathrm{N} 1$ & $2.640(1)$ \\
$\mathrm{La} 2-\mathrm{N} 2$ & $2.480(3), 2.595(3)$ \\
$\mathrm{La} 2-\mathrm{N} 3$ & $2.569(3), 2.722(3), 3.058(1)$ \\
$\mathrm{La} 2-\mathrm{N} 4$ & $2.730(2)$ \\
\hline $\mathrm{Ga}-\mathrm{N} 1$ & $1.967(2)$ \\
$\mathrm{Ga}-\mathrm{N} 2$ & $1.998(3)$ \\
$\mathrm{Ga}-\mathrm{N} 3$ & $1.968(3)$ \\
$\mathrm{Ga}-\mathrm{N} 4$ & $1.904(1)$ \\
\hline
\end{tabular}

